eISSN: 2659-6482

DOI: https://doi.org/10.14201/pmrt.26415

\title{
UN ACERCAMIENTO A LA DEFINICIÓN DE MÚSICA DE RAÍZ TRADICIONAL VENEZOLANA A PARTIR DE LOS ENSAMBLES DE MÚSICA VENEZOLANA INSTRUMENTAL DESDE 1973
}

\section{An Approach to the Definition of Traditional Venezuelan Music Based on Ensembles of Instrumental Venezuelan Music since 1973}

\author{
Miguel PORRAS BECERRA \\ (Universidad de Salamanca) \\ jmiguelporras@gmail.com
}

RESUMEN: Desde los años setenta en Venezuela se ha generado un movimiento de ensambles instrumentales de música venezolana, apegados a la tradición, pero que dan un paso más en composiciones, arreglos y técnicas, siendo difícil poder enmarcarlos en una forma de música específica. A partir de las ideas de música popular y música tradicional, nos acercamos a definir un concepto que nos ayude a entender la propuesta estética de dichas agrupaciones.

Palabras clave: música tradicional; música venezolana; música popular; música instrumental.

ABSTRACT: Since the 1970s, a movement of Venezuelan music instrumental ensembles has been generated in Venezuela, attached to tradition, but which go one step further in compositions, arrangements and techniques, being difficult to frame them in a specific form of music. From the ideas of popular music and traditional music, we approach to define a concept that helps us understand the aesthetic proposal of these groups. 
MIGUEL PORRAS BECERRA

UN ACERCAMIENTO A LA DEFINICIÓN DE MÚSICA DE RAÍZ TRADICIONAL VENEZOLANA

A PARTIR DE LOS ENSAMBLES DE MÚSICA VENEZOLANA INSTRUMENTAL DESDE 1973

Keywords: traditional music; Venezuelan music; popular music; instrumental music.

A partir de la década de los setenta del siglo XX, comienza en Venezuela un importante movimiento de ensambles de música instrumental, donde el repertorio que van a ejecutar se basa en los géneros de música venezolana, pero dando un paso más allá en lo que se venía haciendo en aspectos esenciales como el repertorio, la ejecución y los arreglos musicales. Esto debido básicamente a cuatro grupos: Luis Laguna y su Venezuela 4, Grupo Raíces de Venezuela, El Cuarteto y el Ensamble Gurrufío.

Gran cantidad de músicos y grupos van a tener un punto en común, una música a medio camino de la académica, el folklore y el jazz, donde los recursos de uno y de otro se aprovechan encontrando un nuevo sonido, teniendo a la música venezolana como medio de desarrollo.

Estos ensambles han desarrollado una estética y un lenguaje propios, haciendo que se dificulte encasillarlos dentro de la delgada frontera que tienen los conceptos de música popular, música tradicional, música típica, mesomúsica y/o world music. Es así que es necesario disertar sobre estos conceptos para tener un acercamiento adecuado a dichos grupos y su música, no para definir de manera categórica uno u otro concepto, sino, por el contrario, lo que se busca es tener una definición para poder entablar una relación con los lectores y los oyentes a los que se les presenten este tipo de agrupaciones.

Esto también nos lleva a definir o intentar definir la noción de música venezolana de raíz tradicional, que en nuestra consideración es la categoría, si hiciera falta, más cercana para denominar la música que generan estas agrupaciones. Ese concepto también va unido al de música venezolana, que a priori está claro y definido, pero, si indagamos con detenimiento, nos damos cuenta de que es algo complejo y hasta cierto punto desconocido, determinado por una historia política hegemónica, que con el pasar de los años se ha ido ampliando, extendiéndose y, por qué no, actualizándose.

\section{POPULAR}

Para comenzar es elemental revisar las acepciones sobre popular, la Real Academia Española (RAE) ${ }^{1}$ nos dice, por ejemplo, que arte popular es el cultivado por artistas con frecuencia anónimos y fundado en la tradición. También nos indica

1 https://www.rae.es/ 
que aire popular es una canción o tocata bailable propia y característica del pueblo. Y, por último, cultura popular como conjunto de las manifestaciones en que se expresa la vida tradicional de un pueblo.

De lo presentado podemos encontrar como característica que lo popular manifiesta algo conocido por todos, además de estar vinculado al pueblo, el más llano. En el caso del arte (la música) hablamos de autores anónimos, donde el estudio no está presente, tenemos entonces la más que conocida controversia entre popular/academia.

En el mismo orden de ideas, el músico, profesor, escritor y folklorista venezolano Luis Felipe Ramón y Rivera define como música popular «... toda aquella música de factura relativamente moderna, con raíz tradicional y en el caso venezolano... a los joropos, merengues, valses y bambucos» (1990: 190). Es de recordar que esta definición es resultado de las ideas de la segunda mitad del siglo XX venezolano. A pesar de mencionar géneros típicos venezolanos, que se corresponden con el repertorio de las agrupaciones, no es un concepto funcional para los conceptos actuales de popular, pero si es interesante saber la preocupación que tenía por precisar estos tipos de músicas, su temprana definición se diluye en lo que devino en el concepto de música popular.

Por otra parte, Ana María Ochoa (2003) comenta que el término música popular es ambiguo, ya que puede referirse tanto al folklore o a la música en contextos urbanos, así como también se puede hablar de lo conocido, lo que está de moda. Por su parte, José Peñín (2003) también reconoce la ambigüedad del término popular, y como ejemplo de ello indica que popular puede ser la salsa que se toca en los cerros caraqueños y también puede ser la Quinta o Novena Sinfonía de Ludwig van Beethoven, repertorio de miles de orquestas en el mundo.

Podemos decir que la música popular es un término dinámico, cambiante, que se adapta al momento en que está. Actualmente podemos decir que la música comercial, la música que está de moda, lo que también se denomina música urbana, pertenece a ese catálogo que se titula música popular. En fin, el concepto de música popular ha derivado en muchas formas musicales, haciendo difícil encajar en este renglón las propuestas de los ensambles que estamos revisando.

\section{TRADICIONAL}

Por otra parte, las definiciones de popular están muy cercanas a tradición (tradicional). Ya Ramón y Rivera asoma que la música popular tiene raíz tradicional. Para Josep Martí dentro de la música popular está la música tradicional, «la cual se supone depositaria de nuestras personalidades étnicas» (2000: 221). Pareciera que habláramos de términos iguales, pero el concepto popular es más amplio y envuelve distintas realidades. El término tradición se acerca al folklore y el término popular se acerca a las masas, a lo urbano, a lo más conocido. 
De la misma manera que con el término popular, tenemos la voz tradición (tradicional) en la RAE, donde indica que es la transmisión de noticias, composiciones literarias, doctrinas, ritos, costumbres, etc., hecha de generación en generación y/o el conjunto de rasgos propios de unos géneros o unas formas literarias o artísticas que han perdurado a lo largo de los años. Y con respecto a tradicional tenemos que sigue las ideas, normas o costumbres del pasado.

En ese orden de ideas, Ochoa (2003: 95), parafraseando a Bauman, nos dice que «La palabra tradición entonces pasará a nombrar tanto un proceso de transmisión como los elementos mismos que se trasmiten en ese proceso ("la tradición") y el folklore quedará como espacio para nombrar la conflictiva temporalidad de la modernidad». Ochoa continúa explicando que se identificó

... el folklore con la tradición y a la tradición con el pasado, confundiendo el pasado con un estatismo atemporal: se supone que el folklore «no cambia». Asílos portadores del folklore fueron reducidos a un tiempo sin historia. Es este el marco ideológico que contribuye a un proceso de naturalización de la relación músicas locales-región/nación-identidad, en donde se identifica un género musical con un lugar y con una esencia cultural y sonora.

[...] [Allí] se llevó a cabo un proceso de homogeneización cultural de la nación donde construir la nación implicaba escoger un género musical para que la representara, proceso que generalmente implicó conflicto de orden de valores de lo regional, de lo racial y de lo estético $(2003: 95,96)$.

Resulta de mucha importancia lo antes expuesto, acercándonos a un concepto más operativo. Encontramos a la tradición envuelta en lo popular, con una cercanía al folklore, pero con la capacidad de desarrollarse y dejarse influenciar por otras tendencias, es decir, no es estática. Sin necesariamente caer en lo popular, da cuenta de una personalidad definida que además se apoya en el proceso de identidad/ nacional, que es otro punto importante, las músicas nacionales, que, como vemos, pasa por esos procesos de homogenización a través de la tradición.

\section{TÍPICO}

Sin embargo, en Venezuela, a la música tradicional, en años anteriores a la década de los setenta, se la denominó música típica; de hecho, está muy extendida en todo el país la institución de las Orquestas Típicas de cada estado, por ejemplo: la Orquesta Típica Merideña o la Orquesta Típica del Táchira. Al punto de que hay una Orquesta Típica Nacional, fundada en abril de 1953 por Luis Felipe Ramón y Riviera, declarada Patrimonio Cultural de la Nación en el $2008^{2}$.

2 http://cnm.gob.ve/?p=412 
MIGUEL PORRAS BECERRA

UN ACERCAMIENTO A LA DEFINICIÓN DE MÚSICA DE RAÍZ TRADICIONAL VENEZOLANA

A PARTIR DE LOS ENSAMBLES DE MÚSICA VENEZOLANA INSTRUMENTAL DESDE 1973

De este término no se ha realizado un debate formal, quedó en el uso específico para ese tipo de agrupaciones, mientras los músicos y agrupaciones alrededor de esas orquestas comenzaron a usar el término tradicional y/o popular. La RAE nos dice que típico es algo peculiar de un grupo, país, región, época, etc. Como podemos ver, esa peculiaridad la vemos en los rasgos de esta música, que pueden asociarse a un grupo/región, en este caso a un país, Venezuela.

No obstante, entendemos que el uso del término tradición abarca un contexto más amplio para la definición de una música con tantas características. Probablemente, el desuso del término típico tiene que ver con lo atípico de las propuestas musicales de los ensambles; casi todas pretenden una novedad desde el punto de vista estético, eso sí, manteniendo un vínculo con la tradición.

\section{MESOMÚSICA}

Es justo repasar otro concepto que desde los años sesenta del siglo pasado se expuso, sobre todo en Latinoamérica, y nos habla de esa música que está en un espacio intermedio, conceptualmente hablando. Aunque esta definición no es funcional para los fines de este artículo, bien nos sirve para tener referencia de los estudios sobre lo popular y tradicional, o lo no académico, que se vienen haciendo desde mitad del siglo XX.

El musicólogo argentino Carlos Vega propone un concepto para esa música que no es culta y tampoco es folklórica, él la denomina mesomúsica, y explica que «... es el conjunto de creaciones funcionalmente consagradas al esparcimiento (melodías con o sin texto), a la danza de salón, a los espectáculos, a las ceremonias, actos, clases, juegos, etcétera, adoptadas o aceptadas por los oyentes de las naciones culturalmente modernas... Convive en los espíritus de los grupos urbanos al lado de la "música culta" y participa en la vida de los grupos rurales al lado de la música folklórica» (Vega, 1966: 168-169).

Coriún Aharonián (1997), compositor y musicólogo uruguayo, comenta que lo propuesto por Vega es un estudio acerca de la música popular o de las músicas populares, el primero producido sobre este campo tomado como un todo, además de ser una reflexión temprana y no muy madurada hecha por Vega y Lauro Ayestarán, su colega uruguayo.

Este concepto de mesomúsica no se ha desarrollado mucho más, probablemente Vega no tuvo la contundencia ni el tiempo para defender y desarrollar más sus ideas. Algunos de sus seguidores han tratado de continuar esa línea de investigación sin muchos resultados, aunque la persistencia en definir música popular ha acaparado el interés de la mayoría de los investigadores. Puede ser también que estos estudios «quedan arrinconados debido al hecho de que la ciencia es todavía imperialista, y en el asíllamado Tercer Mundo necesitamos el visto bueno de los 
MIGUEL PORRAS BECERRA

UN ACERCAMIENTO A LA DEFINICIÓN DE MÚSICA DE RAÍZ TRADICIONAL VENEZOLANA

A PARTIR DE LOS ENSAMBLES DE MÚSICA VENEZOLANA INSTRUMENTAL DESDE 1973

centros metropolitanos hasta para incorporar un término científico» (Aharonián, 1997: 62-63).

José Peñín hace un apunte interesante acerca de la mesomúsica en el caso venezolano, señalando que en las realidades argentinas o europeas se puede calificar esa música que está entre lo académico y lo folklórico como mesomúsica, «pero en Venezuela y en otras partes de América, es muy difícil ubicar un estrato medio porque tenemos además de lo folklórico otra realidad musical vigente, variada y multiétnica que son las naciones indígenas, cada una con su propio sistema musical» (2003: 65).

Como vemos en estas definiciones tenemos solo un indicio de un tema muy trabajado y estudiado y aun así sin acuerdos generales sobre estas distinciones. Todos estos conceptos están en continua revisión, pero, a pesar de esto, es de suma importancia tener claro a qué (tipo de) música nos referimos cuando hablamos de las agrupaciones de música instrumental venezolana a partir de 1973.

Peñín hace un comentario muy acertado y es que «En síntesis, podemos diferenciar en Venezuela dos tipos de música popular de masas, una de raigambre tradicional venezolana, nacionalista y otra de carácter internacional occidental o simplemente foránea» (Peñín, 2003: 70). Es decir, que, de todo lo antes revisado y expuesto, el concepto «tradicional»o «música tradicional» es el más adecuado, desde nuestro punto de vista, la tradición como parte de la música popular, pero heredera de las costumbres, dinámica, al punto de que se mezcla con la contemporaneidad, sin dejar al lado el folklore. Y para ser un poco más estrictos, agregar el término raíz permite acercarnos mejor a las agrupaciones que desarrollan una música de vanguardia con una identidad definida, así tendríamos un estudio acerca de las agrupaciones de música de raíz tradicional instrumental venezolanas en los últimos cuarenta años.

\section{WORLD MUSIC}

Por último, es necesario mencionar brevemente la idea de world music, una categoría comercial donde conviven muchas formas de música, y se podría incluir esta que denominamos de raíz tradicional. Algunas agrupaciones como Onkora o Caracas Sincrónica han tenido que autodefinirse como de world music para conseguir entrar en algunos circuitos de conciertos y poder presentar sus trabajos fuera de Venezuela.

«A finales de los 80, la industria discográfica creó oficialmente una nueva categoría de mercado llamada World Music (“música del mundo”, música internacional o músicas étnicas en algunos mercados de América Latina)»(Ochoa, 2003: 28), para así poder responder a una clasificación de músicas locales que para entonces no existía. Obviamente, al catalogarlas de determinada manera, se van a aplicar 
parámetros unificadores para poder definir esas músicas y tener un catálogo a la vez que variado agrupado en una misma etiqueta.

Tenemos entonces que esta categoría comercial permitió mercadear mejor este tipo de músicas. Ya existía un público ávido, pero, al estar etiquetados bajo varios renglones (étnicas, folclóricas, tropical music, etc.), no había una identificación. «En pocas palabras, la categoría nace como un proyecto clasificatorio vinculado a una estrategia comercial que permite mediar la relación entre productores y consumidores» (Ochoa, 2003: 30). Además del world music tenemos world beat y new age, categorías relacionadas entre sí, que facilitan el vínculo con los consumidores (Cook, 2012).

A continuación disertaremos sobre la definición de música venezolana, para poder acercarnos a la música propuesta por las agrupaciones y músicos que estamos revisando.

\section{MÚSICA VENEZOLANA}

De esta manera llegamos a definir o intentar definir la noción de música venezolana, ya que, al hablar de tradición, hablamos de costumbres de un lugar geográfico específico, pero cuando hablamos de países suelen ser muchos kilómetros de geografía y muchos años de historia los que se necesitan para enmarcar una nacionalidad, una identidad, un sentimiento nacional.

A grandes rasgos y para fines de lo que estamos tratando, hablaremos de dos presidentes venezolanos que fueron los pioneros en promover las ideas de nación, Antonio Guzmán Blanco (1829-1899), presidente de Venezuela en tres ocasiones (1870-1877, 1879-1884 y 1886-1888), y Juan Vicente Gómez (1857-1935), quien fue un dictador y gobernó el país desde 1908 hasta su muerte en 1935.

Con Guzmán Blanco tenemos la reformulación del proyecto nacional con vista a la integración de Venezuela como país orgánico. «En este marco, la creación musical va a entrar en un proceso de comunicación interna entre los elementos musicales provenientes del folklore, y la tradición de la academia, para dar pie a la aparición de manifestaciones del nacionalismo musical en el campo de la música académica» (Rodríguez, 2000: 191).

Si bien es cierto que con Guzmán Blanco se inicia un período de construcción de la identidad venezolana, este inicio está marcado por las ideas de resaltar la figura de los héroes de la patria y las glorias del proceso independentista. Esto obviamente se ve en todos los campos. En la música específicamente, los himnos y cantos patrióticos van a formar parte importante de esa idea de nación.

Como podemos ver, formar una figura de nación corresponde a una dirigencia política con necesidades de unificar a través de relatos comunes una historia hegemónica, donde todo lo que ocurre alrededor funciona para ese fin. Anderson 
MIGUEL PORRAS BECERRA

UN ACERCAMIENTO A LA DEFINICIÓN DE MÚSICA DE RAÍZ TRADICIONAL VENEZOLANA

A PARTIR DE LOS ENSAMBLES DE MÚSICA VENEZOLANA INSTRUMENTAL DESDE 1973

(1993: 23) define la nación como «una comunidad política imaginada como inherentemente limitada y soberana». En esta primera etapa de identidad venezolana, además de la independencia como tema central, mirar a Europa y en especial a Francia van a ser características del quehacer venezolano. En el arte en general, muchos jóvenes estudiantes fueron becados para ir a París a empaparse de los acontecimientos artísticos y culturales del momento.

Sin embargo, musicalmente hablando, el primer movimiento nacionalista va a comenzar hacia 1920 , ya que «...Venezuela entró en un período de unificación nacional que vio una avalancha de tradiciones inventadas provenientes de varias facciones importantes de diferentes ámbitos sociales y políticos» (Aponte, 2008: 2-3). El precedente a un movimiento nacionalista musical lo podemos ver en la formación del Círculo de Bellas Artes de Caracas en 1909.

Para el compositor, crítico musical, pedagogo y diplomático José Antonio Calcaño (1900-1978), la historia de la música en Venezuela se puede comenzar a escribir con propiedad a partir del año de 1919, cuando comenzó el movimiento que todavía se estaba desarrollando en los años cincuenta. Para él, en ese momento no podía narrarse ni valorarse con justicia, porque aún no estaba concluido dicho movimiento. Es necesario tener la perspectiva del tiempo para poder saber su alcance $(2019)^{3}$.

Cuando el dictador militar Juan Vicente Gómez llegó al poder en 1908, se propuso restaurar la confianza internacional, perdida durante varias décadas de agitación política en el país, y atraer inversiones extranjeras. Además de gestionar una visión de nación más homogénea y entenderla como un país total, un paso más del proyecto «guzmancista». En la cultura se comenzó a diseñar una idea propia de Venezuela y en la música:

El movimiento hacia la renovación buscó introducir la música moderna del arte europeo en el país y crear un público masivo para ella. Un aspecto central de este objetivo fue la creación de una moderna infraestructura musical (orquestas sinfónicas, coros, escuelas de música, tecnología, etc.). En su esfuerzo por unir a la gente y ganar legitimidad tanto en el país como en el extranjero, el movimiento de renovación se dirigió al nacionalismo cuya manifestación final se expresó en la creación de un repertorio musical que podría ser reconocido como venezolano. Sin embargo, al determinar las marcas de identificación nacional en la música, el nacionalismo participó en un proceso mucho más amplio de inventar tradiciones, porque en ese momento no existía en Venezuela la música-cultura de alcance nacional. Por lo tanto, la élite musical participó en la invención de la tradición mediante la elaboración de un discurso de autenticidad que les permitió, primero, crear códigos

3 La primera edición de La ciudad y su música es de 1958, en este trabajo se está revisando la edición más reciente de 2019. 
nacionales de comunicación cultural, y segundo, estimular la composición musical adoptando esos códigos. (Aponte, 2008: 12-13)

Para el hijo del compositor venezolano Evencio Castellanos, el también músico Pablo Castellanos, el nacionalismo musical venezolano era como un estilo musical elegido por un grupo de compositores activos en Caracas entre 1920 y 1960 (Aponte, 2008). Estos compositores adoptaron formas folklóricas del país como punto de partida de sus composiciones y así comenzaron a configurar una identidad nacional.

Es de destacar que el joropo fue el género musical que más se utilizó, convirtiéndolo en la música nacional, siendo este género típico de la región de Los Llanos, que curiosamente comparte frontera con Colombia, teniendo joropo a ambos lados de la frontera. Además, hay muchas formas de joropo, se puede decir que existen tres grandes grupos: el llanero, el oriental y el central, además de sus distintos subgéneros.

No es casual que para la invención del sentimiento nacionalista venezolano se usara principalmente la música típica de la región de Los Llanos, región donde hubo un gran contingente de guerreros en la lucha por la independencia, siempre presente en la memoria colectiva venezolana, como, por ejemplo, los lanceros de Páez. De Páez también se puede mencionar su inclinación por la música, en sus campamentos siempre había canto y baile, era común el fandango que era como se conocía al joropo en esa época, así como los cantos patrióticos entonados por los soldados (Calcaño, 2019).

Con el joropo, podemos encontrar un camino muy explícito del recorrido del nacionalismo musical venezolano. Como punto de partida, en 1914 se compone una zarzuela denominada Alma Llanera $a^{4}$, donde la introducción es un joropo; la letra estuvo a cargo de Bolívar Coronado y la música de Pedro Elías Gutiérrez, quien se desempeñaba como director de la Banda Marcial de Caracas. La pieza luego pasó a ser parte del repertorio obligado de la banda para cerrar los conciertos; desde ese momento y hasta la actualidad ha sido denominada el segundo himno nacional, tanto así que en 2014 la Asamblea Nacional (AN) aprobó el proyecto para la Declaratoria del Alma Llanera como Bien de interés cultural, en el centenario de su estreno ${ }^{5}$.

4 Alma Llanera por Juan Vicente Torrealba recuperado de https://youtu.be/zuoXj_YN5mU el 1 de marzo de 2020. tural/

5 https://albaciudad.org/2014/09/an-declaro-el-alma-llanera-como-bien-de-interes-cul- 
Este movimiento nacionalista tiene su momento más conspicuo con la obra $\mathrm{La}$ Cantata Criolla de Antonio Estévez, estrenada en 1954, la letra nace del mítico poema venezolano Florentino el que cantó con el Diablo, escrito por Alberto Arvelo Torrealba, el cual narra una competencia de canto o contrapunteo entre Florentino y el Diablo típico del joropo llanero. La obra está escrita para orquesta, coro y dos solistas dividida en tres partes. Es decir, hablamos de una obra académica de corte nacionalista, tomando los elementos del folklore venezolano, específicamente de Los Llanos, donde el joropo es el protagonista.

A mitad del siglo XX, durante el gobierno de Pérez Jiménez, presidente de Venezuela entre 1953 y 1958, la idea de joropo que se dio distaba mucho de la realidad. El musicólogo venezolano Rafael Salazar comenta que los medios de comunicación impusieron un joropo estilizado, cambiando su indumentaria e inventando movimientos de baile que no eran los propios del Llano, hablamos de las danzas nacionalistas, que estaban por todo el país (Salazar, 2014).

Rafael Salazar ha realizado un trabajo acucioso sobre el joropo, podemos encontrar otra visión sobre el hecho de por qué se considera una música nacional. Se considera que el joropo es derivado del fandango, baile popular en España hacia finales de siglo XVII, pero Salazar ubica al fandango en África y llega a América con los negros esclavos.

El fandango luego de su viaje a España vuelve a América, pero con otras características, mezclado sobre todo con aires andaluces «y se convierte desde México a la Patagonia en el alma sonora de Hispanoamérica. Si no hubiese existido el Fandango, no hay música nacional en nuestra América, o mejor dicho, sería otra música distinta» (Salazar, 2014). Es muy importante que para Salazar el fandango, en sus distintas formas, es núcleo principal de casi todas las músicas nacionales americanas, en el caso de Venezuela serían el joropo y sus variantes.

Aprovechando la ocasión y para contraponer lo que venimos definiendo sobre el joropo como música nacional, cabe el comentario que recientemente en el I Simposio Virtual El arpa y su relación con el joropo, de la Universidad Pedagógica Experimental Libertador y el Instituto Pedagógico de Caracas, llevado a cabo el 26 de junio de 2020, el ponente 'Cheo' Hurtado mencionó la hipótesis, que luego ratificó en una entrevista privada que se le realizó, donde otorga al vals (venezolano) la denominación de la verdadera música nacional.

'Cheo' tiene claro que en todas las regiones del país existe una forma de vals, arropadas bajo la métrica del $3 / 4$, pero con las particularidades locales, rápidos, lentos, románticos, llaneros, andinos, zulianos, orientales. Ciertamente, es solo una hipótesis que el mismo Hurtado comenta que quiere profundizar, pero dado

6 Cantata Criolla por la Orquesta Sinfónica Juvenil y Coro Sinfónico de los Llanos Venezolanos, recuperado de https://youtu.be/mo84lIUQBUQ el 1 de marzo de 2020. 
MIGUEL PORRAS BECERRA

UN ACERCAMIENTO A LA DEFINICIÓN DE MÚSICA DE RAÍZ TRADICIONAL VENEZOLANA

A PARTIR DE LOS ENSAMBLES DE MÚSICA VENEZOLANA INSTRUMENTAL DESDE 1973

el caso vale la pena mencionarlo en estas líneas (Asdrúbal ‘Cheo’ Hurtado Comunicación personal, 26-04-2020).

Sobre cómo el vals se incorporó a la música venezolana y su total hegemonía a finales del siglo XIX y principios del XX, José Antonio Calcaño expresa:

Podemos, pues, estar seguros de que fue en el tercer cuarto del siglo XIX cuando se impuso el vals entre nosotros.

Hay matices que diferencian el valse de distintos países, como lo es el francés, más fluido que el vienés, que tiende a largar el segundo tiempo lo que da la impresión de un pequeño salto en ese sitio. En Venezuela, como sucedió también en otros países latinoamericanos, adquirió el valse una riqueza rítmica desconocida en Europa. Fue, indudablemente una labor anónima de nuestro pueblo la que dio este resultado. Los ejecutantes populares, al adoptar el valse, fueron incorporándole diseños rítmicos del joropo, elementos del seis por ocho de algunos bailes españoles o nativos, del tipo del zapateado, y, además, toda una serie abundante de síncopas de origen tal vez africano, y no sabemos hasta qué punto de fuentes indígenas. Toda esta amalgama ha debido producirse el correr de los años entre la época de los Monagas y la de Guzmán Blanco, y así llegamos a tener en el valse criollo una superposición de diferentes ritmos y hasta diferentes compases, que hacen en nuestro valse una especie de contrapunto de ritmo... el valse llegó a ser casi una locura durante muchos años. (2019: 455-457)

Como podemos ver, antes de que el joropo se erigiera como una música nacional, el vals venezolano ya había hecho lo propio. No vamos a definir si es el vals o el joropo el género nacional, como hemos visto responden a momentos distintos, y tanto uno como el otro han adoptado características de las zonas donde se interpretan, creando particularidades que hacen que ambos géneros tengan sus pares por toda Venezuela.

Para finalizar podemos decir que para construir una música nacional los gobiernos buscan recursos en el folklore y en la tradición. Pero es muy difícil encontrar una tradición que identifique a todo un país. En la tradición, no hay las fronteras determinadas por las organizaciones políticas nacionales. Los géneros musicales se van a solapar con sus fronteras vecinas, por ejemplo, para Venezuela, Colombia es su vecino principal, y comparten por la región del Llano el joropo y por los Andes el bambuco.

La música venezolana es producto de un largo proceso de mestizaje, que podemos situar con la llegada de las primeras vihuelas al país en el siglo XVI, específicamente en Cubagua. Teniendo como protagonistas a los indígenas de la región, los europeos llegados con la conquista y los africanos traídos como esclavos por los conquistadores. Estos tres grupos no son, ni por asomo, tan homogéneos como algunos han planteado, pues cada uno de ellos tiene componentes variopintos que hacen aún más rica toda la mezcla. 
De Europa llegaron ingleses, holandeses, alemanes y portugueses, pero la mayoría de ellos vino desde España. Entre los mismos españoles observamos incluso características distintas propias de andaluces, vascos, gallegos, canarios y algún que otro árabe que todavía formaba parte de la península. Desde África, los esclavos arribaron desde varios puntos geográficos: Senegal, Angola y Congo, entre otros, mientras que, en América, y en el caso venezolano, cada región geográfica tenía sus propias sociedades de nativos distintas unas de otras. En este escenario y bajo las condiciones ya conocidas que se dieron con el proceso de conquista (siglo XV) y posterior colonización (a partir del siglo XVI), se empezó a tejer una trama muy variada que dio lugar, entre otras cosas, a la música venezolana.

Por supuesto, todos esos conceptos y nociones de Venezuela se empezaron a conocer bien entrada la República a mediados del siglo XIX. Así, cada región fue adoptando los elementos propuestos a partir de estos grandes grupos para dar paso a los géneros musicales autóctonos, en algunos casos, géneros venidos de la Península Ibérica y adaptados a las condiciones idiosincrásicas de la región.

A todo esto, hay que sumar que, a principio del siglo XX, cuando apenas se estaba formando un perfil nacional, hubo mucha influencia de los medios de comunicación, radio, cine y televisión, de países como Estados Unidos y México, dejando consigo muchas más formas de música que involucrar.

Demás está decir que no existe una música nacional, existen muchos géneros que conviven en una nación, a ese conjunto se le puede denominar música venezolana, pero más por una necesidad taxonómica que por acercamiento estético. La separación geográfica también indica una diferencia en la música, pero, a pesar de eso, al nombrar gaita zuliana, joropo tuyero o calipso del Callao damos por sentado que es música venezolana. Además, «hay por igual otras manifestaciones como la salsa, parte ya de nuestra identidad, así como otros géneros que se han vinculado de alguna u otra forma en nuestra cultura, dando pie a las fusiones y confusiones actuales; parte preponderante de nuestro folklore urbano» (Báez, 2010).

\section{BIBLIOGRAFÍA}

Ahorián, C. (1997). Carlos Vega y la teoría de la música popular. Un enfoque latinoamericano en un ensayo pionero. Revista Musical Chilena, Año LI, julio-diciembre n. ${ }^{\circ}$ 188, 61-74.

Anderson, B. (1993). Comunidades imaginadas. Reflexiones sobre el origen y la definición de nacionalismo. México: Fondo de Cultura Económica.

Aponte, P. (2008). The invention of the national in Venezuelan art music, 1920-1960. Tesis doctoral para acceder al grado de Doctorado en Filosofía de la Universidad de Pittsburgh. Estados Unidos de América. 
Báez, A. (2010). ¿Por qué la música venezolana no es conocida internacionalmente? Prodavinci. Disponible en: http://historico.prodavinci.com/ [Última consulta: 1 de febrero de 2020].

Calcaño, J. A. (2019). La ciudad y su música: crónica musical de Caracas. Caracas, Venezuela: Universidad Central de Venezuela. Ediciones de la Biblioteca EBUC.

Cook, N. (2012). De Madonna al canto gregoriano. Una muy breve introducción a la música. Madrid: Alianza Editorial.

Martí, J. (2000). Más allá del arte. La música como generadora de realidades sociales. Barcelona: Deriva Editorial.

Ochoa, A. M. ${ }^{a}$ (2003). Músicas locales en tiempos de globalización. Buenos Aires: Grupo editorial Norma.

Peñín, J. (2003). Música popular de masas, de medios, urbana o mesomúsica venezolana. Revista de Música Latinoamericana, vol. 24, 62-94.

Porras, M. (2020). Entrevista al músico Asdrúbal 'Cheo’ Hurtado el 26-04-2020. Caracas-Venezuela. Sin transcribir. No publicado.

Ramón y Rivera, L. F. (1990). La música folklórica de Venezuela. Tercera edición. Caracas: Monte Ávila.

Rodríguez, F. (2000). Música y nacionalismo durante el Guzmanato (1870-1888). Revista Musical de Venezuela, n. ${ }^{\circ}$ 41. Caracas: Fundación Vicente Emilio Sojo, 191-208.

Salazar, R. (2014). Los orígenes del joropo, relatados por el investigador Rafael Salazar. Desde Bagdad, África y España hasta Venezuela. Disponible en: https://albaciudad. org/2014/08/los-origenes-del-joropo-relatados-por-el-investigador-rafael-salazar-desde-bagdad-africa-y-espana-hasta-venezuela/ [Ultima consulta: 15 de marzo de 2020]. Vega, C. (1966). La Mesomúsica. Revista Polifonía, n. ${ }^{\circ} 131 / 132$. Buenos Aires, $2 .^{\circ}$ trimestre.

\section{WEBGRAFÍA}

https://albaciudad.org

http://cnm.gob.ve

https://www.rae.es/ 
